\title{
SUBSÍDIO ESTATÍSTICO À INTERPRETAÇÃO DE DADOS DO COMPLEXO GABRO-ANORTOSÍTICOO DE ANGOLA
}

\author{
ZENAIDE C.G. SILVA* e MANUEL A.G. SILVA**
}

\begin{abstract}
STATISTICAL CONTRIBUTION TO THE STUDY OF THE GABBROANORTHOSITE COMPLEX OF ANGOLA. The Gabbro-anorthosite Complex of SW Angola covers $18,000 \mathrm{~km}^{2}$ that extend into Namibia and has been the subject of recent geological studies published elsewhere. The samples available from the total area of exposure in Angola are thought to represent the composition of the medium part of the intrusion and their chemical analysis provided a large number of data that deserved statistical study. The objectives of the work undertaken are twofold: 1. identification of a small number of parameters capable of adequately characterizing the sampling, instead of the 23 variables corresponding to major and trace elements contents of 55 analyzed samples and 2. grouping the samples by criteria of physical similarity such as to draw conclusions eventually hidden or only weakly indicated by variation diagrams in the aforementioned publications. Factor analysis and clustering techniques, based on current criteria of numerical taxonomy, were thus performed and die results are described and interpreted. The numerical calculations were mostly conducted with the SPSS-PC + package in a microcomputer with a $40 \mathrm{Mb}$ hard disk. The interpretation of earlier results led to several analyses performed without some samples whose high content of some trace elements or oxides made sort of "singular". The results show that three factors, namely conbinations of, respectively, $(\mathrm{MgO}, \mathrm{Ni}, \mathrm{Cr}),\left(\mathrm{Ba}, \mathrm{K}_{2} \mathrm{O}\right)$ and $\left(\mathrm{TiOa}, \mathrm{P}_{2} \mathrm{O}_{5} \mathrm{Y}\right)$ may be selected for the geochemical characterization of the Complex. These components reflet opposite effects that olivine and plagioclase, the dominant cumulus phases in the rocks, play in the chemistry of the Complex. Clustering the samples strengthened the realization of the existence of bottom-top (or west to east) correlation between the variation of essential components of the plagioclase and olivine and the aforementioned geographic orientation.
\end{abstract}

Keywords: Statistical analysis, gabbro-anorthosite complex, factor analysis, cluster analysis.

\begin{abstract}
RESUMO O Complexo Gabro-Anortosítico de Angola cobre $18.000 \mathrm{~km}^{2}$ que se estendem pela Namíbia e tem sido objeto de estudos geológicos recentes encontrados em várias publicações. Neste trabalho, procurou-se: 1. a identificação de um numero pequeno de parâmetros que possam caracterizar a amostragem de modo adequado, ao invés das 23 variáveis, que correspondem aos teores em elementos maiores e menores obtidos por meio de análises químicas de 55 rochas e 2 . agrupar as amostras utilizando critérios tais de similaridade física que pudessem indicar algumas afinidades eventualmente ainda não detectadas ou pouco evidenciadas a partir dos diagramas de variação utilizados nas publicações referidas. Foram utilizadas técnicas de análise de fatores e de agrupamentos baseados em critérios de taxonomia numérica e os resultados obtidos estão descritos bem como sua interpretação. Os cálculos numéricos foram elaborados com a utilização do programa SPSS-PC + em microcomputador com disco de $40 \mathrm{Mb}$. A interpretação dos primeiros resultados indicou a necessidade de se realizar outras análises para uma amostragem parcial, eliminando-se algumas amostras com teores muito elevados de alguns elementos. Os resultados mostram que três fatores, principalmente as combinações de $(\mathrm{MgO}, \mathrm{Ni}, \mathrm{Cr}),\left(\mathrm{Ba}, \mathrm{K}_{2} \mathrm{O}\right)$ e $\left(\mathrm{TiO}_{2}, \mathrm{P}_{2} \mathrm{O}_{5}, \mathrm{Y}\right)$, podem ser selecionados para uma caracterização geoquímica do Complexo. $\mathrm{O}$ agrupamento das amostras confirmou a tese de que há uma correlação base-topo com a variação das componentes essenciais da olivina e do plagioclásio e a orientação geográfica oeste-leste.
\end{abstract}

Palavras-chaves: Análise estatística, complexo gabro-anortosítico, análise fatorial, análise de agrupamentos.

INTRODUÇÃO No extremo sul de Angola ocorre uma das maiores "massas" de anortosito do globo, cujo conhecimento geológico se reveste de especial importância, tanto pela contribuição que virá oferecer à compreensão da evolução da crosta no sul da África, como pelas implicações econômicas que esta ocorrência poderá ter.

Esta intrusão, que cobre cerca de $18.000 \mathrm{~km}^{2}$ em área do território angolano, prolonga-se pela Namíbia por cerca de 30 $\mathrm{km}$ a sul do Rio Cunene. E mais conhecida na literatura geológica como o Complexo Gabro-Anortosítico de Angola. Está encaixado em rochas metamórficas pré-cambrianas de vários ciclos, compreendendo o Complexo xisto-quartzítico anfibolítíco, gnaisses, migmatitos e rochas granitóides. Na sua parte leste, está coberto pelas areias do Kalahari. O complexo tem caráter estratiforme, especialmente na sua parte norte, onde o anortosito é escuro e bandado. Na porção sul, estas características são menos pronunciadas, ocorrendo aí também um tipo distinto de anortosito, de coloração mais clara (anortosito branco), cuja aparência é comparada à do anortosito do tipo massive.

Alguns anos atrás, antes que a guerra que persiste deste
1974 o impedisse, foi feita um coleta de amostras na área deste complexo, conforme referido em Simpson (1970). Essas amostras foram sujeitas a várias análises que conduziram a resultados e interpretações que constam de alguns trabalhos publicados (Süva 1987,1988,1989).

As análises químicas de 55 dessas amostras, representativas dos tipos de rochas que ocorrem na área exposta, compreenderam a determinação de elementos maiores, aqui expressos em porcentagem dos pesos dos óxidos destes elementos $\left(\mathrm{SiO}_{2}\right.$, $\mathrm{TiO}_{2}, \mathrm{Al}_{2} \mathrm{O}_{3}, \mathrm{Fe}_{2} \mathrm{O}_{3}, \mathrm{FeO}, \mathrm{MnO}, \mathrm{MgO}, \mathrm{CaO}, \mathrm{Na}_{2} \mathrm{O}, \mathrm{K}_{2} \mathrm{O}$, $\mathrm{P}_{2} \mathrm{O}_{5}$ ) e de elementos menores ( $\mathrm{Rb}, \mathrm{Sr}, \mathrm{Y}, \mathrm{Zr}, \mathrm{Nb}, \mathrm{V}, \mathrm{Cr}, \mathrm{Ni}$, $\mathrm{Cu}, \mathrm{Zn}, \mathrm{Ba}, \mathrm{Th})$, expressos em partes por milhão (ppm) (Tab. 1.A e 1.B).

A simples análise dessas tabelas permite observar que há um certa consistência na variação de determinados elementos dentro de cada grupo petrográfico, variação esta relacionada com a posição estratigráfica da rocha. A variação é ressaltada em elementos como por exemplo, $\mathrm{SiO}_{2}$, que, dentro de cada grupo petrográfico, tem valores mais baixos nas rochas provenientes do lado oeste e valores mais elevados nas que provêm do lado leste do maciço, correspondendo, respectiva-

\footnotetext{
* Departamento de Geologia, Faculdade de Ciências, Universidade de Lisboa, Campo Grande, 1700 Lisboa

** Centro de Informática, Laboratório Nacional de Tecnologia Industrial, 1699 Lisboa Codex
} 
mente à base e ao topo da intrusão na área exposta, conforme já referido por Silva (1987).

A existência de 23 variáveis neste conjunto de 55 amostras aconselha um esforço de interpretação qualitativa dos dados que identifique, dentre todas as variáveis, um número muito mais reduzido que, por si ou em grupo, permita caracterizar o maciço.

Por outro lado, também se procura atingir o objetivo de descobrir relações entre as próprias amostras de modo que ajude a evidenciar aspectos da evolução do maciço e, em certos casos, da própria orientação deste, assim coadjuvando critérios próprios da geologia.

Estes objetivos justificaram que se fizesse um estudo de natureza estatística, aplicando técnicas de análise fatorial e de agrupamentos na busca de resultados do tipo referido acima. Essas técnicas estão divulgadas de vários modos na literatura e não parece relevante transcrevê-las neste trabalho, sendo bastante referir os dois textos em que se foi buscar grande parte do apoio, o de Sneath \& Sokal (1973) e o de Davis (1973).

A correlação entre 1 . as conclusões baseadas na análise de fatores e na associação das amostras em agrupamento e 2. a realidade física é objeto de estudo que também será apresentado neste trabalho.

CARACTERIZAÇÃO DA AMOSTRAGEM As amostras estudadas cobrem toda a área de exposição do Complexo. As amostras analisadas localizam-se geograficamente como se mostra na figura 1 e são identificadas, neste texto, por um número seqüencial até 55 , número total de amostras. A escolha destas amostras foi feita de modo que aproximasse, o melhor possível, as seções tranversais ao corpo rochoso. Correspondem, de 1 a 8 a anortositos puros, de 9 a 13 a anortositos brancos, de 14 a 21 a anortositos contendo até $10 \%$ de piroxênios, de 22 a 29 a anortositos gabróicos, de 30 a 37 a gabros e gabros anortosíticos, de 38 a 42 a noritos e de 43 a 55 a troctolitos. Em todos estes grupos de amostras, excetuando os anortositos brancos e os noritos, os primeiros números correspondem a amostras provenientes da parte oeste e os últimos às da parte leste da área de amostragem, que se supõe corresponderem, respectivamente, à base e ao topo da intrusão na porção exposta do Complexo. Os valores de cada uma das vinte e três variáveis citadas, para cada uma das 55 amostras, não havendo valores em falta, podem ser consultados na tabela 1 .

ANÁLISE DE FATORES Ao dispor de 23 variáveis para as 55 amostras, decidiu-se calcular a medida da adequação da amostragem (MSA) de cada variável, para estabelecer se haveria razão para eliminar alguma das variáveis. Utílizou-se o critério referido por Norusis (1986) em que, ao relacionarem-se coeficientes de correlação entre variáveis e correlações parciais, sempre que estas são pouco significativas, as MSA são próximas de 1 .

Aceitando o critério de eliminar as variáveis cujo MSA seja inferior a 0,5 , atinge-se o rubídio $(\mathrm{Rb})$ com 0,35 , o nióbio $(\mathrm{Nb})$ também com 0,35 e o tório (Th) com 0,37. A medida de Kaiser-Mayer-Olkin para avaliar a adequação global da amostragem, para o caso das 20 variáveis restantes, é 0,703 que se considera aceitável.

O teste de esfericidade de Bartlett deu o valor 1,685 e o nível de significância próximo de zero, reforçando a hipótese de que as variáveis podem combinar-se em fatores.

Ao longo do trabalho, foram feitas determinações com as 23 variáveis iniciais (Caso C23) ou com as 20 que resultaram após a eliminação de Rb, $\mathrm{Nb}$ e Th (Caso C20).

Amostragem Completa A matriz de correlação (23 x 23) mostra valores não diagonais que evidenciam relações importantes entre variáveis. Concentrando a atenção na correlação positiva, o maior elemento da matriz é $\mathrm{r}_{7,19}=0,9299$, que

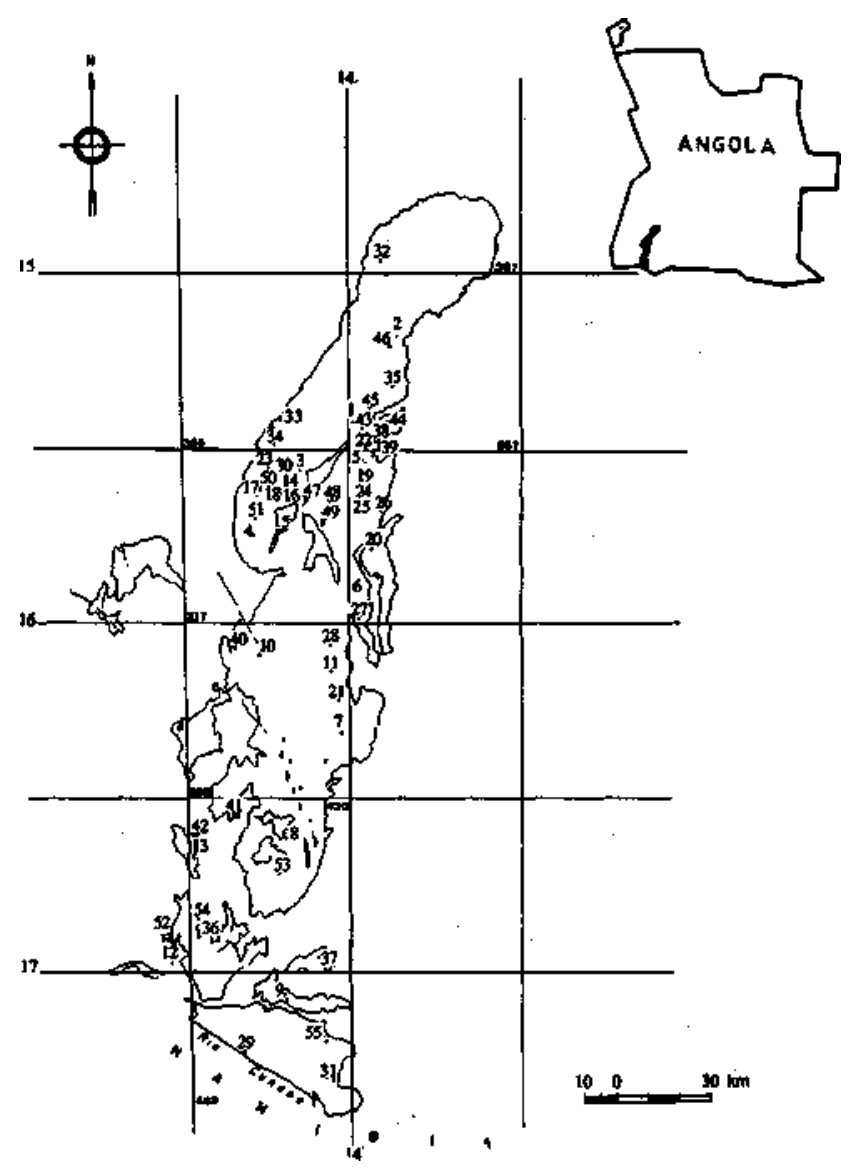

Figura 1 - Localização da área de estudo e localização das amostras (mostrada no esboço do Complexo Gabro-Anortosítico de Angola)

Figure 1 - Location of the area and samples (shown on a sketch map of the Gabbro-anorthosite Complex of Angola)

corresponde a $\mathrm{MgO}$ e Ni. Outra variável com forte correlação com outras é o FeO com $\mathrm{MnO}(0,8727)$, com o $\mathrm{MgO}(0,8585)$ e com $\mathrm{Zn}(0,8577)$. Por sua vez, o $\mathrm{K}_{2} \mathrm{O}$ mostra correlação positiva forte com $\mathrm{Rb}$ e com o Ba.

Estas verificações, na prática, correspondem a afinidades geoquímicas entre aqueles elementos e, neste caso particular, refletem as composições químicas das fases minerais presentes nas rochas em estudo. Não obstante, a busca sistemática de fatores que caracterizassem a "comunidade das 23 variáveis" no coletivo das 55 amostras aconselhou que também se procurasse extrair fatores a partir da niatriz no caso $\mathrm{C} 20$.

É utilizada, neste capítulo, a fatorização mediante a análise das componentes principais, o que exige a determinação dos valores e vetores característicos ou próprios da matriz de correlação. Os vetores e valores próprios de uma matriz simétrica têm propriedades bem conhecidas e técnicas computacionais de extração rotineiras (Bathe \& Wilson 1976).

À primeira componente principal corresponde a combinação linear de Variáveis que é responsável pela maior porcentagem de variação da amostragem, e as seguintes aparecem ordenadas decrescentemente por essa propriedade.

São apresentados na tabela 2, os valores próprios achados para os casos em que se consideram as 23 e as 20 variáveis, respectivamente. Mostra-se, ainda, a porcentagem da variação atribuível à combinação linear das variáveis que define cada um dos correspondentes setores próprios. 
Tabela IA - Análise química das rochas (elementos maiores em \% óxidos)

Table 1A - Chemical analysis of rock samples (major elements in \% oxides)

\begin{tabular}{|c|c|c|c|c|c|c|c|c|c|c|c|}
\hline $\mathbf{N}^{\mathbf{2}}$ & $\mathrm{SiO}_{7}$ & & & $\mathrm{Fe}_{2} \mathrm{O}_{3}$ & $\mathrm{FeO}$ & Mno & $\mathrm{MgO}$ & $\mathrm{CAO}$ & $\mathrm{N}_{2} \mathrm{O}_{2}$ & $\mathrm{~K}_{2} \mathrm{O}$ & \\
\hline & & $\pi 8$ & & & 0.30 & & T,OT & म, & 398 & & \\
\hline & $\begin{array}{l}4,99 \\
47,76\end{array}$ & 10 & 31,5 & $\begin{array}{l}0.39 \\
0.46\end{array}$ & $\begin{array}{l}022 \\
0.30\end{array}$ & : & $\frac{91}{21}$ & $\begin{array}{l}5,14,14 \\
10,2\end{array}$ & 5 & & \\
\hline & & & & & & & 7 & & 2,89 & & \\
\hline & & $\begin{array}{l}0,1 \\
0,1\end{array}$ & $\begin{array}{l}27.45 \\
28.14\end{array}$ & 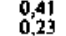 & 7 & & $\begin{array}{l}0,83 \\
0,03\end{array}$ & & $\begin{array}{r}4,80 \\
4,86\end{array}$ & & \\
\hline & & & & & & & & & 4.80 & & \\
\hline & & & $\begin{array}{l}30,07 \\
23,80\end{array}$ & 16 & $\begin{array}{l}0.22 \\
4,10\end{array}$ & & $\begin{array}{l}0,88 \\
7,36\end{array}$ & & $\begin{array}{l}3,79 \\
2,95\end{array}$ & ${ }_{15}^{26}$ & \\
\hline & & & & 0 & 4,18 & 0111 & 2,82 & 5 & 4,02 & & \\
\hline & & $1, x$ & 27,30 & $\begin{array}{l}1.39 \\
0.39\end{array}$ & $\begin{array}{l}1,94 \\
0.97\end{array}$ & & $\begin{array}{l}1,04 \\
1,4 !\end{array}$ & & $\begin{array}{l}70 \\
90\end{array}$ & 36 & \\
\hline & & & & & & & & & 79 & & \\
\hline & & & & & 0,72 & 008 & 2,22 & & 2,30 & 6 & \\
\hline & & & & & 89 & & 0,91 & & 39 & & \\
\hline & & 0.31 & $\left\{\begin{array}{l}2970 \\
2570\end{array}\right.$ & $\begin{array}{l}76 \\
30\end{array}$ & 3,192 & $\begin{array}{l}0,04 \\
0.07\end{array}$ & $\begin{array}{l}2.28 \\
3.23\end{array}$ & 88 & 2.60 & $\begin{array}{l}0,18 \\
0,20\end{array}$ & \\
\hline & & & & & 391 & 0,07 & 3.00 & 99 & .85 & 68 & 0,0 \\
\hline & & & & & $\begin{array}{l}0,17 \\
2,09\end{array}$ & 0,10 & 159 & $\begin{array}{r}11,00 \\
9,3\end{array}$ & $\begin{array}{l}4.49 \\
4,15\end{array}$ & $\begin{array}{l}1+4 \\
19 \\
19\end{array}$ & \\
\hline & & & & & 7 & & 5 & 87 & 52 & & \\
\hline & & & & & & & & & 3.85 & 58 & \\
\hline & $\begin{array}{l}54, \\
50 .\end{array}$ & & $\begin{array}{l}24 \\
37\end{array}$ & 965 & 3 & & 2,22 & & $\begin{array}{l}4,26 \\
3,14\end{array}$ & 8 & \\
\hline & & & & & 2, & & & & & & \\
\hline$\frac{2}{2}$ & & & & & 3,88 & & & & 431 & 8 & \\
\hline & & & & & 7 & & & & & & \\
\hline 3 & & & & & 24 & 33 & & & $\begin{array}{l}50 \\
55 \\
0\end{array}$ & & \\
\hline & & & & & & & & & . & & 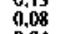 \\
\hline & & & & & & 0,04 & & & & & \\
\hline 3 & & & & & & & & & & & \\
\hline 3 & & & & & & & & 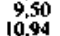 & & 33 & 0.0 \\
\hline & & & & & & & & & & & \\
\hline & & & & & & & & & & & \\
\hline & & & & & & & & & & & \\
\hline & & & & & & & & & & & \\
\hline & & & & & & & & & & & \\
\hline & & & & & & & & & & & \\
\hline & & & & & & & & & & & \\
\hline & & & & & & & & & & & \\
\hline & & & & & & & & & & & \\
\hline & & & & & & & & & & & \\
\hline 5 & & & & & 1 & & & & & $E$ & 0,0 \\
\hline & & & & & & & & & & & \\
\hline & & & & & & & & & & & \\
\hline
\end{tabular}

Foi verificado que os três primeiros fatores da análise sem $\mathrm{Rb}, \mathrm{Nb}$, Th explicam $73,5 \%$ da variação total e que quatro fatores atingem $80,5 \%$.

No caso de serem consideradas todas as variáveis, o mesmo número de fatores explica apenas $66,6 \%$ e $73,9 \%$, sendo necessários cinco para atingir o limiar dos $80 \%$.

Para melhor sistematização, separam-se a seguir as análises das duas classes de amostras, dando-se maior atenção interpretativa à que corresponde apenas a 20 variáveis.

TODAS AS VARIÁVEIS (C23) Considerem-se apenas três fatores, $F_{1}, F_{2}$ e $F_{3}$. A matriz de fatores correspondente exprime o peso que, para cada variável normalizada, têm $\mathrm{F}_{1}$, $\mathrm{F}_{2}$ e $\mathrm{F}_{3}$. Reproduzem-se abaixo, para ilustração, apenas as correlações dos fatores $\mathrm{F}_{1}, \mathrm{~F}_{2}$ e $\mathrm{F}_{3}$ com as variáveis sempre que o módulo de um dos coeficientes da matriz excede 0,80 .

Os valores dos coeficientes indicam o peso de cada fator na representação da variável normalizada e, escolhendo apenas a correlação positiva, vê-se que $\mathrm{F}_{1}$ está claramente ligado, por exemplo, a $\mathrm{FeO}, \mathrm{MnO}, \mathrm{MgO}, \mathrm{Cu}$ e $\mathrm{Zn}$, enquanto $\mathrm{F}_{2}$ se liga ao $\mathrm{BaeK}_{2} \mathrm{O}$.

A determinação da composição dos fatores a partir deste tipo de análise da matriz cheia é portanto possível, mas difícil pela presença de muitos coeficientes de valor semelhante, ou, pelo menos, não desprezável. Procedeu-se, por isso, à rotação pelo método Varimax.

Examinando a matriz dos fatores após a rotação aparecem as seguintes composições:

Fator A - Ba, $\mathrm{Rb}, \mathrm{K}_{2} \mathrm{O}$

Fator $\mathrm{B}$ - $\mathrm{Ni}, \mathrm{MgO},(\mathrm{Cr})$

Fator C - Zn, $\left(\mathrm{TiO}_{2}, \mathrm{FeO}, \mathrm{Fe}_{2} \mathrm{O}_{3}, \mathrm{~V}, \mathrm{Cu}\right)$
Tabela 1B-Análise química das rochas (elementos menores em ppm)

Table 1B - Chemical analysis of rock samples (minor elements in ppm)

\begin{tabular}{|c|c|c|c|c|c|c|c|c|c|c|c|c|}
\hline & $\mathbf{R b}$ & & & & & & & & & & & \\
\hline & & & & $?$ & 1 & & & & & & & \\
\hline 4 & & 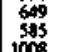 & 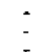 & 4 & & $\begin{array}{l}\mathbb{H}_{0}^{*} \\
10\end{array}$ & $\begin{array}{l}26 \\
69\end{array}$ & 证 & 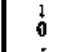 & & & \\
\hline & & $\mid \begin{array}{l}108 \\
80\end{array}$ & 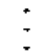 & $\begin{array}{l}43 \\
4 \\
40\end{array}$ & & $\begin{array}{l}\text { 19: } \\
39\end{array}$ & $\begin{array}{l}\overline{27} \\
\frac{17}{26}\end{array}$ & \begin{tabular}{|l|l}
$\frac{17}{27}$ \\
$\frac{27}{27}$
\end{tabular} & 8 & 15 & & \\
\hline & $\begin{array}{l}0 \\
\frac{1}{2} \\
\frac{1}{2}\end{array}$ & $\begin{array}{l}595 \\
776\end{array}$ & & $\dot{\mathbf{3}}$ & & 吾 & $\begin{array}{l}51 \\
51\end{array}$ & 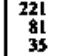 & $\begin{array}{c}10 \\
8 \\
1\end{array}$ & 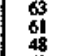 & & \\
\hline & 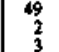 & $\begin{array}{l}616 \\
662 \\
652\end{array}$ & 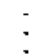 & 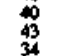 & $\stackrel{\bar{a}}{\mathbf{j}}$ & $\begin{array}{l}\frac{19}{19} \\
11\end{array}$ & 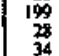 & $\begin{array}{l}\mathbf{3 5} \\
38\end{array}$ & ${ }_{11}^{i}$ & 6 & & \\
\hline & 1 & $\begin{array}{l}3.560 \\
90\end{array}$ & & $\begin{array}{l}33 \\
\mathbf{2}\end{array}$ & 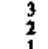 & $\begin{array}{l}26 \\
71\end{array}$ & $\begin{array}{l}32 \\
132 \\
32\end{array}$ & $\begin{array}{l}52 \\
62 \\
3\end{array}$ & 14 & (18) & & \\
\hline & $\frac{2}{1}$ & 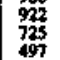 & & $\frac{43}{37}$ & $\frac{0}{2}$ & $\begin{array}{l}9 \\
26 \\
31\end{array}$ & 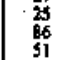 & 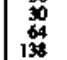 & ]$_{13}^{\frac{1}{3}}$ & 84 & & \\
\hline & 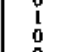 & 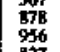 & $\begin{array}{l}4 \\
0\end{array}$ & $\begin{array}{l}3 \\
0 \\
0\end{array}$ & $\begin{array}{l}6 \\
8\end{array}$ & 18 & $\begin{array}{l}3 \\
34 \\
35\end{array}$ & $\begin{array}{l}3 \\
3 \\
31 \\
310\end{array}$ & ${ }_{i 1}^{4}$ & 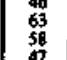 & & \\
\hline & $\begin{array}{l}7 \\
4\end{array}$ & $\frac{10}{2}$ & & $\begin{array}{l}0 \\
4\end{array}$ & & $\begin{array}{l}160 \\
30\end{array}$ & $\begin{array}{l}31 \\
\frac{11}{5}\end{array}$ & 需 & & & & \\
\hline & & $\begin{array}{l}77 \\
7\end{array}$ & $i$ & $\frac{5}{27}$ & & 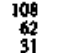 & $\begin{array}{l}917 \\
57\end{array}$ & $\mid \begin{array}{l}199 \\
137\end{array}$ & 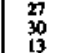 & 9 & & \\
\hline & & $\begin{array}{l}5.56 \\
362 \\
414\end{array}$ & 0 & $\begin{array}{l}\mathbf{5 6} \\
40 \\
\end{array}$ & $\begin{array}{l}1 \\
0 \\
0 \\
0\end{array}$ & $\begin{array}{l}199 \\
20 \\
20\end{array}$ & $\begin{array}{l}51 \\
31 \\
47\end{array}$ & $\begin{array}{l}21 \\
32 \\
36\end{array}$ & $\begin{array}{l}14 . \\
16 \\
9\end{array}$ & 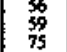 & 2 & \\
\hline & $\begin{array}{l}1 \\
3 \\
3\end{array}$ & 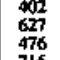 & 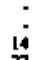 & $\begin{array}{l}78 \\
17 \\
94\end{array}$ & 2 & $\begin{array}{l}\frac{108}{60} \\
160 \\
100\end{array}$ & $\begin{array}{l}276 \\
37 \\
162\end{array}$ & 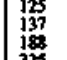 & 敢 & 82 & 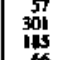 & \\
\hline & 17 & $\begin{array}{l}1559 \\
1776\end{array}$ & & 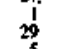 & $\frac{6}{3}$ & $\begin{array}{l}74 \\
157 \\
107\end{array}$ & $\begin{array}{l}72 \\
177\end{array}$ & $m^{7}$ & $5 !$ & 116 & 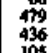 & $\frac{6}{3}$ \\
\hline & 0 & $\begin{array}{l}142 \\
142 \\
003 \\
50\end{array}$ & 0 & 7 & & $\begin{array}{l}20 \\
57\end{array}$ & $\begin{array}{c}19 \\
19 \\
127\end{array}$ & 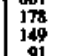 & $\bar{x}$ & 70 & 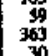 & \\
\hline & 0 & $\begin{array}{l}40 \\
651\end{array}$ & & & $\frac{2}{3}$ & $\frac{21}{3}$ & 70 & 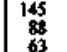 & $\frac{2}{7}$ & $\begin{array}{l}57 \\
\text { s. }\end{array}$ & 1233 & 1 \\
\hline & & $\begin{array}{l}452 \\
359 \\
484\end{array}$ & $\begin{array}{c}1 \\
0 \\
0 \\
0\end{array}$ & $\$$ & 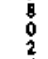 & 13 & 8 & 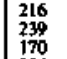 & $1_{13}^{\frac{7}{3}}$ & $\frac{54}{62}$ & $\begin{array}{l}\frac{31}{36} \\
\frac{36}{62}\end{array}$ & \\
\hline & & 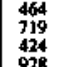 & & $\stackrel{20}{3}$ & & & $\begin{array}{c}x_{212} \\
37 \\
3 \\
3\end{array}$ & 277 & $\frac{14}{8}$ & 焉 & & \\
\hline
\end{tabular}

Tabela 2 - Valores próprios e\% de variação por fator Table 2 - Eigen values and $\%$ of variance per factor

\begin{tabular}{|c|c|c|c|c|c|}
\hline \multicolumn{3}{|c|}{ Todas as Varjáweis } & \multicolumn{3}{|c|}{ Sem Rb, Nb, Th } \\
\hline Fmor & Valor proptio & SVtriatucia & Faror & Valar profeio & 6) Varimein \\
\hline 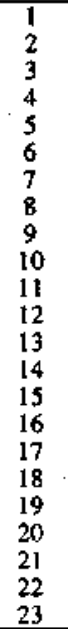 & $\begin{array}{l}9,003 \\
4,216 \\
2,102 \\
1,679 \\
1,310 \\
0,980 \\
0,807 \\
0,601 \\
0,530 \\
0,456 \\
0,323 \\
0,281 \\
0,192 \\
0,152 \\
0,119 \\
0,082 \\
0,055 \\
0,050 \\
0,027 \\
0,017 \\
0,009 \\
0,005 \\
0,003\end{array}$ & $\begin{array}{r}39,1 \\
18,3 \\
9,1 \\
7,3 \\
5,7 \\
4,3 \\
3,5 \\
2,6 \\
2,3 \\
2,0 \\
1,4 \\
1,2 \\
0,8 \\
0,7 \\
0,5 \\
0,4 \\
0,2 \\
0,2 \\
0.1 \\
0.1 \\
0,0 \\
0,0 \\
0,0\end{array}$ & $\begin{array}{c}1 \\
2 \\
3 \\
4 \\
5 \\
6 \\
7 \\
8 \\
9 \\
10 \\
11 \\
12 \\
13 \\
14 \\
15 \\
16 \\
17 \\
18 \\
19 \\
20\end{array}$ & $\begin{array}{l}8,981 \\
3,893 \\
1,828 \\
1,408 \\
0,964 \\
0,615 \\
0,549 \\
0,469 \\
0,338 \\
0,280 \\
0,227 \\
0,138 \\
0,099 \\
0,083 \\
0,054 \\
0,028 \\
0,020 \\
0,018 \\
0,006 \\
0,004\end{array}$ & $\begin{array}{r}44,9 \\
19,5 \\
9,1 \\
7,0 \\
4,8 \\
3,1 \\
2,7 \\
2,3 \\
1,7 \\
1,4 \\
1,1 \\
0,7 \\
0,5 \\
0,4 \\
0,3 \\
0,1 \\
0,1 \\
0,1 \\
0,0 \\
0,0\end{array}$ \\
\hline
\end{tabular}

em que entre parêntesis estão variáveis com menor participação.

$\mathrm{O}$ aparecimento do Rb e a "indefinição" de um dos fatores porque integra muitas variáveis, ainda mais aconselharam a análise de C20.

Acrescente-se que uma verificação da representatividade, em termos de variação, destes fatores mostra, e.g., que 
Tabela 3 - Correlações $>0,80$ (23 variáveis)

Table 3 - Correlations $>0.80$ (23 variables)

\begin{tabular}{|c|c|c|c|}
\hline Fatores & & & \\
Variáveis & $F_{1}$ & $F_{2}$ & $F_{3}$ \\
\hline $\mathrm{Al}_{2} \mathrm{O}_{3}$ & $-0,94$ & $-0,18$ & 0,09 \\
$\mathrm{FeO}$ & 0,93 & $\mathbf{0 , 0 3}$ & 0,04 \\
$\mathrm{MnO}$ & 0,88 & 0,07 & 0,03 \\
$\mathrm{MgO}$ & 0,90 & $-0,16$ & $-0,33$ \\
$\mathrm{~K}_{2} \mathrm{O}$ & $-0,22$ & 0,80 & $-0,37$ \\
$\mathrm{Cu}$ & 0,86 & 0,09 & 0,12 \\
$\mathrm{Zn}$ & 0,89 & 0,22 & 0,13 \\
$\mathrm{Ba}$ & $-0,08$ & 0,90 & $-0,12$ \\
\hline
\end{tabular}

representam $96 \%$ da variação do $\mathrm{MgO}$, mas apenas $7 \%$ no caso do $\mathrm{Nb}$ e $10 \%$ no caso do Th.

A variação do $\mathrm{Zr}$ também se acha muito mal representada neste modelo, que apenas inclui $12 \%$ da variação total desse elemento.

CASO DAS 20 VARIÁVEIS (C20) Neste caso, definido ao serem eliminadas as variáveis $\mathrm{Rb}, \mathrm{Nb}$ e $\mathrm{Th}$ em todas as 55 amostras, obteve-se a matriz dos fatores, a qual continua a ter elementos relativamente próximos, em módulo, tornando difícil a determinação da composição fatorial.

Operou-se, então, uma rotação pelo método Varimax e obteve-se uma fatorização das variáveis que se pode discriminar assim:

Fator I - $\mathrm{MgO}, \mathrm{Ni}, \mathrm{Al}_{2} \mathrm{O}_{3}(-), \mathrm{Cr}$

Fator II - V, $\mathrm{TiO}_{2}, \mathrm{Y}, \mathrm{P}_{2} \mathrm{O}_{5}$

Fator III - $\mathrm{Ba}, \mathrm{K}_{2} \mathrm{O}, \mathrm{Na}_{2} \mathrm{O}, \mathrm{CaO}(-)$

Efetuando, ainda, outra análise de fatores para estas 12 variáveis, três fatores representam $80 \%$ da variação total e o $\mathrm{V}$ perde peso na representação. Se for eliminada a participação de uma variável num fator logo que o correspondente elemento da matriz dos fatores seja inferior em mais de 5\% ao da variável precedente, pelo método Varimax, obtém-se:

$\mathrm{Fl}-\mathrm{Ni}, \mathrm{MgO}, \mathrm{Cr}$

$\mathrm{F} 2$ - $\mathrm{Ba}, \mathrm{K}_{2} \mathrm{O}$

$\mathrm{F} 3-\mathrm{TiO}_{2}, \mathrm{P}_{2} \mathrm{O}_{5}, \mathrm{Y}$

Esta conclusão é corroborada pela rotação oblíqua se, neste caso, apenas se imprimirem os elementos superiores, em módulo, a 0,45 , o que conduz à matriz ordenada, pattern que se mostra na tabela 4 .

Observando a matriz, vê-se que há variação sensível na contribuição de cada fator para a variação. Enquanto, e.g., $\mathrm{F}_{3}$ contribui $65,3 \%\left(0,808^{2}\right)$ para a representação da variância de $\mathrm{P}_{2} \mathrm{O}_{5}, \mathrm{~F}_{1}$ contribui com $94,5 \%\left(0,972^{2}\right)$ para a do $\mathrm{Ni}$.

A matriz dos coeficientes ponderadores score $\hat{e}$ apresentada na tabela 5 .

Esta matriz permite ainda, segundo Norusis (1986, pg. $\mathrm{B}-43$ ), exprimir cada fator em termos das variáveis $\mathrm{Xj}$, com $\mathrm{Fi}=\mathrm{P}_{\mathrm{ij}} \mathrm{Xj}(\mathrm{i}=1,2,3 ; \mathrm{j}=1,2, \ldots, \mathrm{N})$.

De maneira um pouco grosseira, mas aceitável para efeitos qualitativos, pode escrever-se imediatamente:

$\mathrm{F}_{1}=0,247(\mathrm{MgO})+0,253(\mathrm{Cr})+0,27 \mathrm{l}(\mathrm{Ni})$

$\mathrm{F}_{2}=-0,307(\mathrm{CaO})+0,317\left(\mathrm{~K}_{2} \mathrm{O}\right)+0,312(\mathrm{Ba})$

$\mathrm{F}_{3}=0,331\left(\mathrm{TiO}_{2}\right)+0,365\left(\mathrm{P}_{2} \mathrm{O}_{5}\right)+0,326(\mathrm{Y})$

o que reproduz (e quantifica) as conclusões que se obtiveram anteriormente por cuidadosa inspeção das matrizes de fatores.
Tabela 4 - Matriz Pattern (por rotação oblíqua) - 55 amostras Table 4 - Pattern matrix (oblique rotation) - 55 variables

\begin{tabular}{|c|c|c|c|}
\hline \multicolumn{1}{|c|}{ Fatores } & & & \\
Variáveis & $\mathrm{F}_{1}$ & $\mathrm{~F}_{2}$ & $\mathrm{~F}_{3}$ \\
\hline $\mathrm{Ni}$ & 0,972 & $*$ & $*$ \\
$\mathrm{MgO}$ & 0,946 & $*$ & $*$ \\
$\mathrm{Cr}$ & 0,916 & $*$ & $*$ \\
$\mathrm{Al}_{2} \mathrm{O}_{3}$ & $-0,787$ & $*$ & $*$ \\
$\mathrm{Ba}$ & $*$ & 0,902 & $*$ \\
$\mathrm{~K}_{2} \mathrm{O}$ & $*$ & 0,887 & $*$ \\
$\mathrm{CaO}$ & $-0,482$ & $-0,830$ & $*$ \\
$\mathrm{Na}_{2} \mathrm{O}$ & $-0,527$ & 0,666 & $*$ \\
$\mathrm{P}_{2} \mathrm{O}_{5}$ & $*$ & $*$ & 0,808 \\
$\mathrm{TiO}_{2}$ & $*$ & $*$ & 0,795 \\
$\mathrm{Y}$ & $*$ & $*$ & 0,768 \\
$\mathrm{~V}$ & $*$ & $*$ & 0,691 \\
\hline
\end{tabular}

Tabela 5-Matriz ponderaradora Score Table 5-Score matrix

\begin{tabular}{|c|c|c|c|}
\hline $\begin{array}{c}\text { Fatores } \\
\text { Variáveis }\end{array}$ & $\mathrm{F}_{1}$ & $\mathrm{~F}_{2}$ & \multicolumn{1}{c|}{$\mathrm{F}_{3}$} \\
\hline $\mathrm{TiO}_{2}$ & $-0,080$ & 0,063 & 0,331 \\
$\mathrm{Al}_{2} \mathrm{O}_{3}$ & $-0,180$ & $-0,048$ & $-0,079$ \\
$\mathrm{MgO}_{\mathrm{CaO}}$ & 0,247 & $-0,012$ & $-0,052$ \\
$\mathrm{Na}_{2} \mathrm{O}$ & $-0,157$ & $-0,307$ & 0,076 \\
$\mathrm{~K}_{2} \mathrm{O}$ & 0,117 & 0,224 & $-0,001$ \\
$\mathrm{P}_{2} \mathrm{O}_{5}$ & $-0,020$ & 0,317 & $-0,070$ \\
$\mathrm{Y}$ & $-0,051$ & $-0,064$ & 0,365 \\
$\mathrm{~V}$ & 0,023 & $-0,086$ & 0,326 \\
$\mathrm{Cr}$ & 0,253 & 0,024 & 0,267 \\
$\mathrm{Ni}$ & 0,271 & 0,014 & $-0,094$ \\
$\mathrm{Ba}$ & $-0,005$ & 0,312 & 0,0121 \\
\hline
\end{tabular}

Amostragem Reduzida A redução, por conveniência interpretativa, a 52, 51 e a 49 amostras, que se tornará clara ao ler o item sobre análise dos agrupamentos, torna igualmente conveniente uma rápida análise desses dois casos, em especial do primeiro que parece mais significativo pelas razões já expostas ou a expor na interpretação física. A redução de 55 para 52 amostras é feita por exclusão de amostras muito ricas em $\mathrm{Cr}$ e $\mathrm{Ni}$; a redução para 51 amostras, por exclusão de uma amostra muito rica em Ba; e, por fim, a passagem para 49 amostras, por exclusão de amostras com comportamento específico em relação a $\left(\mathrm{P}_{2} \mathrm{O}_{5}, \mathrm{TiO}_{2}, \mathrm{Y}\right)$.

AMOSTRAGEM SEM PICOS DE Ni, Cr e Ba Neste caso, à coleção de 51 amostras associa-se uma medida de Kaiser-Meyer-Olkin que vale 0,72 , e as medidas MSA são consistentemente altas. Os três primeiros valores próprios da matriz de correlação englobam $73,8 \%$ da variação total.

Os elementos preponderantes da matriz dos fatores, após rotação Varimax, são mostrados na tabela 6 mantendo o critério de inserção apenas para casos em que um módulo seja $\geq 0,80$. 
T a he Ia 6 - Matriz dos fatores (51 amostras) Table 6 - Factor matrix

\begin{tabular}{|c|c|c|c|}
\hline Fatores & $F_{1}$ & $F_{2}$ & $F_{3}$ \\
\hline $\mathrm{MgO}$ & - & 0,819 & - \\
$\mathrm{Na}_{2} \mathrm{O}$ & - & 0,907 & - \\
$\mathrm{Ba}$ & - & 0,880 & - \\
$\mathrm{CaO}$ & - & $-0,864$ & - \\
$\mathrm{K}_{2} \mathrm{O}$ & - & 0,856 & - \\
$\mathrm{V}$ & - & - & 0,919 \\
$\mathrm{Cu}$ & - & - & 0,815 \\
\hline
\end{tabular}

Observe-se que, apesar de omitidos na tabela pelo critério usado, o $\mathrm{Ni}$ e o $\mathrm{FeO}$ estão próximos do $\mathrm{MgO}$ (com 0,772 e $0,748)$ e poderia ser lógico incluí-los nesta fatorização, bem como ao Y no fator $\mathrm{F}_{3}$ e à $\mathrm{SiO}_{2}$ e $\mathrm{Sr}$ no fator $\mathrm{F}_{2}$.

CASO DAS 49 AMOSTRAS Este caso parece ter menor interesse, mas a matriz é mostrada na tabela 7 após a rotação oblíqua pattern para os elementos com maiores coeficientes. Os valores não inscritos são inferiores a 0,45 .

Tabela 7 - Matriz Pattern (par rotação oblíqua) - 51 amostras Table 7 - Pattern matrix (oblique rotation) - 51 samples

\begin{tabular}{|c|c|c|c|}
\hline $\begin{array}{c}\text { Fatores } \\
\text { Variáveis }\end{array}$ & $\mathrm{g}_{1}$ & $\mathrm{~g}_{2}$ & $\mathrm{~g}_{3}$ \\
\hline $\mathrm{MgO}$ & 0,885 & - & - \\
$\mathrm{Ni}$ & 0,858 & - & - \\
$(\mathrm{FeO})$ & 0,778 & - & - \\
$\mathrm{CaO}$ & - & $-0,954$ & - \\
$\mathrm{Na} 2 \mathrm{O}$ & - & 0.919 & - \\
$\mathrm{K}_{2} \mathrm{O}$ & - & 0,870 & - \\
$\mathrm{Ba}$ & - & 0,851 & - \\
$\mathrm{V}$ & - & - & 0,990 \\
$(\mathrm{Cu})$ & - & - & 0,736 \\
$(\mathrm{Cr})$ & - & - & 0,706 \\
\hline
\end{tabular}

É preciso não esquecer que estes valores são obtidos desprezando seis amostras com significativo peso e que têm apenas o interesse de proporcionar dados para interpretações de ordem física, sempre que a localização das amostras ou outros critérios o permitam.

As amostras segregadas nesta análise têm os seus valores evidenciados e contrastados com a respectiva média na tabela 8 .

Deve ser salientado que os valores das médias, para alguns elementos cujos conteúdos em certas amostras são elevados, são bastante afetados se forem excluídas essas amostras do conjunto. Exemplos típicos são os referentes a $\mathrm{Cr}$ e Ni, para os quais, ao serem excluídas as amostras 39,42 e 52 , passam a ter como médias 53,2 e 101,8, respectivamente.

A tabela 8 revela valores muito altos de $\mathrm{Cr}$ e Ni e relativamente altos de $\mathrm{MgO}$ nas amostras 39,42 e 52, em contraposição aos valores médios da amostragem. A amostra 13 destacase pelo teor muito alto de $\mathrm{Ba}$ e as amostras 38 e 49 são ricas em Y e P, principalmente.

Excluídas todas estas amostras da análise de homogeneidade ou de dissemelhança, ter-se-ia como variáveis definidoras de três fatores, respectivamente, $(\mathrm{MgO}),\left(\mathrm{Na}_{2} \mathrm{O}, \mathrm{Ba}, \mathrm{CaO}\right.$, $\left.\mathrm{K}_{2} \mathrm{O}\right)$ e $(\mathrm{V}, \mathrm{Cu})$.

Tabela 8 - Amostras singulares Table 8-Singular samples

\begin{tabular}{|c|c|c|c|c|c|c|c|}
\hline An & $357+13$ & 420.11 & 419.13 & $420-12 \mathrm{~A}$ & $357-9$ & 377.46 & Media \\
\hline Varifivel & 39 & 42 & 52 & 13 & 38 & 49 & (55 congars) \\
\hline $\mathrm{SiO}_{2}$ & 46.14 & 47,26 & $42,8]$ & 50,31 & 47,73 & 44,67 & 49,4 \\
\hline $\mathrm{TO}_{2}$ & 98 & 0,52 & 0,66 & 0,38 & 59 & 250 & 47 \\
\hline $\mathrm{Al}_{2} \mathrm{O}_{3}$ & 14,32 & 7,78 & 14,00 & 27,98 & 17,21 & 16,37 & 24,8 \\
\hline $\mathrm{F}_{\varepsilon_{2}} \mathrm{O}_{3}$ & 2,07 & 2,40 & 1,72 & 0,91 & 2,41 & 1,79 & 1,25 \\
\hline Feo & 10,06 & 10.36 & 11,36 & 0,59 & 7,76 & $11,68$. & 3.65 \\
\hline $\mathrm{MnO}$ &, 19 & 0,25 & 0,21 & 0,00 & ,15 & 0,18 & 0,07 \\
\hline $\mathrm{MgO}$ & 11.89 & 22,68 & 18,55 & 1,41 & 8,47 & 9,65 & 4,74 \\
\hline $\begin{array}{c}\mathrm{CaO} \\
\mathrm{Na}_{2} \mathrm{O}\end{array}$ & $\begin{array}{r}11,40 \\
2,17\end{array}$ & $\begin{array}{l}6,03 \\
0,68\end{array}$ & $\begin{array}{l}6.73 \\
1,65\end{array}$ & $\begin{array}{l}8,97 \\
3,79\end{array}$ & $\begin{array}{r}10,94 \\
2,74\end{array}$ & $\begin{array}{l}8.75 \\
2,93\end{array}$ & $\begin{array}{r}10,84 \\
3,30\end{array}$ \\
\hline $\mathrm{K}_{2} \mathrm{O}$ & 0,13 & 0,42 & 0,23 & 2,60 &, 33 & 0,49 & 0,45 \\
\hline$P_{2} \mathbf{O}_{5}$ & 0,14 & 0,04 & 0,02 & 0,00 & 23 & 0,32 & 0,07 \\
\hline $\mathbf{R b}$ & 0 & 22 & 4 & 49 & 3 & 4 & 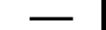 \\
\hline $\mathbf{S} \boldsymbol{T}$ & 716 & 71 & 464 & 616. & 476 & 482 & 652,8 \\
\hline$Y$ & 22 & 0 & 4 & 0 & 14 & $\mathbf{L}$ & 1,07 \\
\hline $\mathrm{Zr}$ & 27 & 5 & 20 & 40 & 54 & 58 & 20,00 \\
\hline $\mathbf{N b}$ & 0 & 3 & 4 & 0 & 2 & 8 & 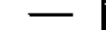 \\
\hline v & 272 & 142 & 78 & 49 & 160 & 94 & 45,3 \\
\hline $\mathrm{Cr}$ & 238 & 805 & 221 & 199 & 162 & 23 & 119,6 \\
\hline $\mathbf{N i}$ & 325 & 801 & 894 & 35 & 188 & 216 & 131,6 \\
\hline $\mathrm{Cu}$ & 80 & 63 & 41 & 0 & 68 & 24 & 19,5 \\
\hline Zn & 88 & 99 & 110 & 37 & 82 & 99 & 57,95 \\
\hline Ba & 66 & 105 & 165 & 253 & 185 & 304 & 190,8 \\
\hline Th & 0 & 0 & 1 & 0 & 2 & 0 & \\
\hline
\end{tabular}

ANÁLISE DE AGRUPAMENTOS

A classificação de amostras por critérios de semelhança permite definir agrupamentos de características homogêneas. A origem e localização geográfica das amostras - por exemplo - podem então ser analisadas e cotejadas por agrupamento, e permitir detectar eventuais afinidades e causalidades que, de outro modo, passariam despercebidas.

As técnicas de fundamentação estatística que permitem o estabelecimento desses conjuntos com o mesmo nível de semelhança exigem a escolha de um critério para quantificar a semelhança das amostras e um critério para se agregar em classes.

Neste estudo, foi adotada a distância euclidiana quadrada, avaliada em relação a todas ou a parte das variáveis e somada para todos os pares possíveis de amostras e a técnica de average linkage no clustering, embutidas no programa de computação utilizado.

Amostragem Completa Neste caso, utiliza-se a amostragem completa (55 amostras) e as variáveis indicadas na seqüência do texto para se definir a distância euclidiana entre as amostras.

É obtido o dendrograma da figura 2, quando se consideram todas as amostras. A matriz da dissemelhança evidencia valores enormes para os casos em que intervém as amostras 39,42 e 52, da ordem de múltiplos de $10^{6}$.

Afora estas três amostras, os valores de dissemelhança são da ordem de $10^{5}$ ou menores (a partir de 2,0).

A figura 3 mostra o dendrograma obtido quando se restringe a medida da dissemelhança às nove variáveis agrupadas na análise de fatores, isto é, $(\mathrm{Ni}, \mathrm{MgO}, \mathrm{Cr}),\left(\mathrm{Ba}, \mathrm{K}_{2} \mathrm{O}, \mathrm{CaO}\right)$ e $\left(\mathrm{P}_{2} \mathrm{O}_{5}, \mathrm{TÍ}_{2}, \mathrm{Y}\right)$.

A presença "singular" das amostras 39,42 e 52 nos gráficos resulta fundamentalmente das distâncias associadas às variáveis intervenientes no primeiro fator como evidencia a figura 4. Verificou-se no estudo, ainda que não se mostre aqui, que as duas variáveis que mais contribuem para a dissemelhança são, por ordem crescente, o níquel e o cromo. 
$0 \mid$
$0 \mid$
$0+1$

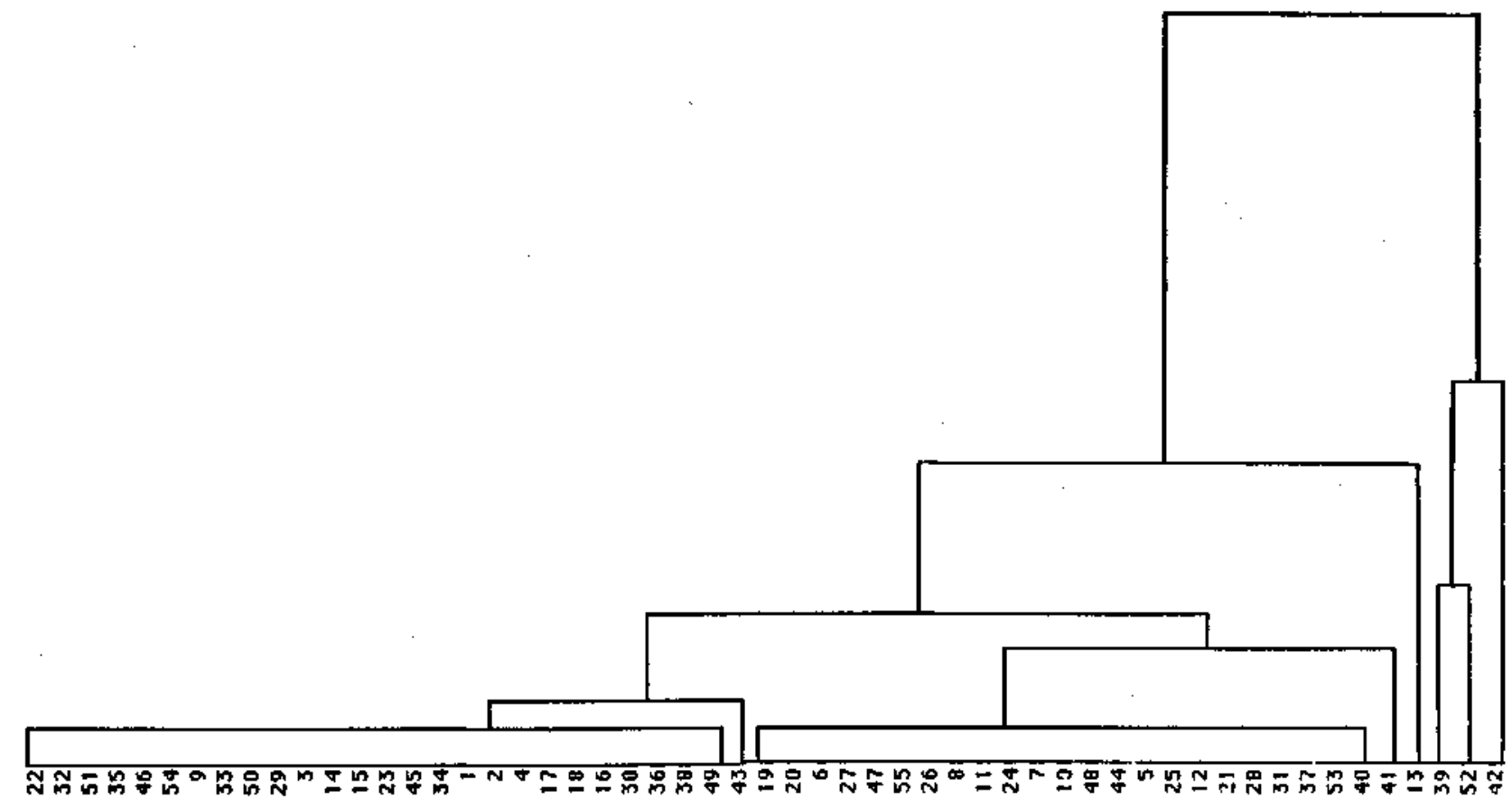

Figura 2 - Amostragem total. Dissemelhança para todas as variáveis

Figure 2 - Total sampling. Dissimilarities for all variables

年

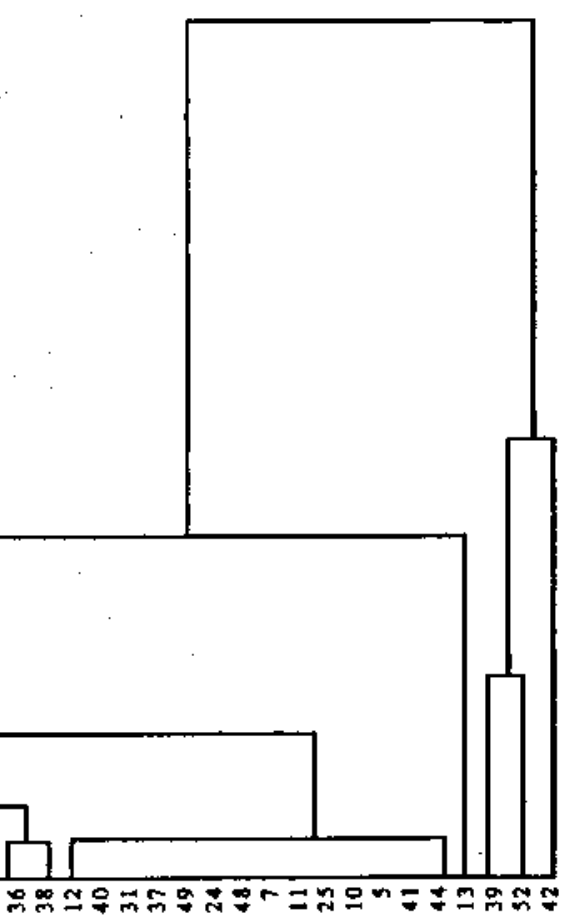

Figura 3 - Amostragem total. Dissemelhança para $\mathrm{MgO}, \mathrm{Ni}, \mathrm{Cr}, \mathrm{CaO}, \mathrm{K}_{2} \mathrm{O}, \mathrm{Ba}, \mathrm{P}_{2} \mathrm{O}_{5}, \mathrm{TiO}_{2}$ e $\mathrm{Y}$

Figure 3 - Total sampling. Disimilarities for $\mathrm{MgO}, \mathrm{Ni}, \mathrm{Cr}, \mathrm{CaO}, \mathrm{K}_{2} \mathrm{O}, \mathrm{Ba}, \mathrm{P}_{2} \mathrm{O}_{5}, \mathrm{THO}_{2}$ and $\mathrm{Y}$

Atendendo a esta diferenciação relativa das amostras 39, 42 e 52, decidiu-se rodar o mesmo tipo de análise de agrupamentos para o subconjunto das restantes 52 amostras, estudo que se reporta a seguir. Ele foi complementado ainda por outro estudo, eliminando, adicionalmente, a amostra 13 e, depois, outras amostras por motivos que se indicam caso a caso.

Amostragens Reduzidas É mostrado, na figura 5, o dendro- 


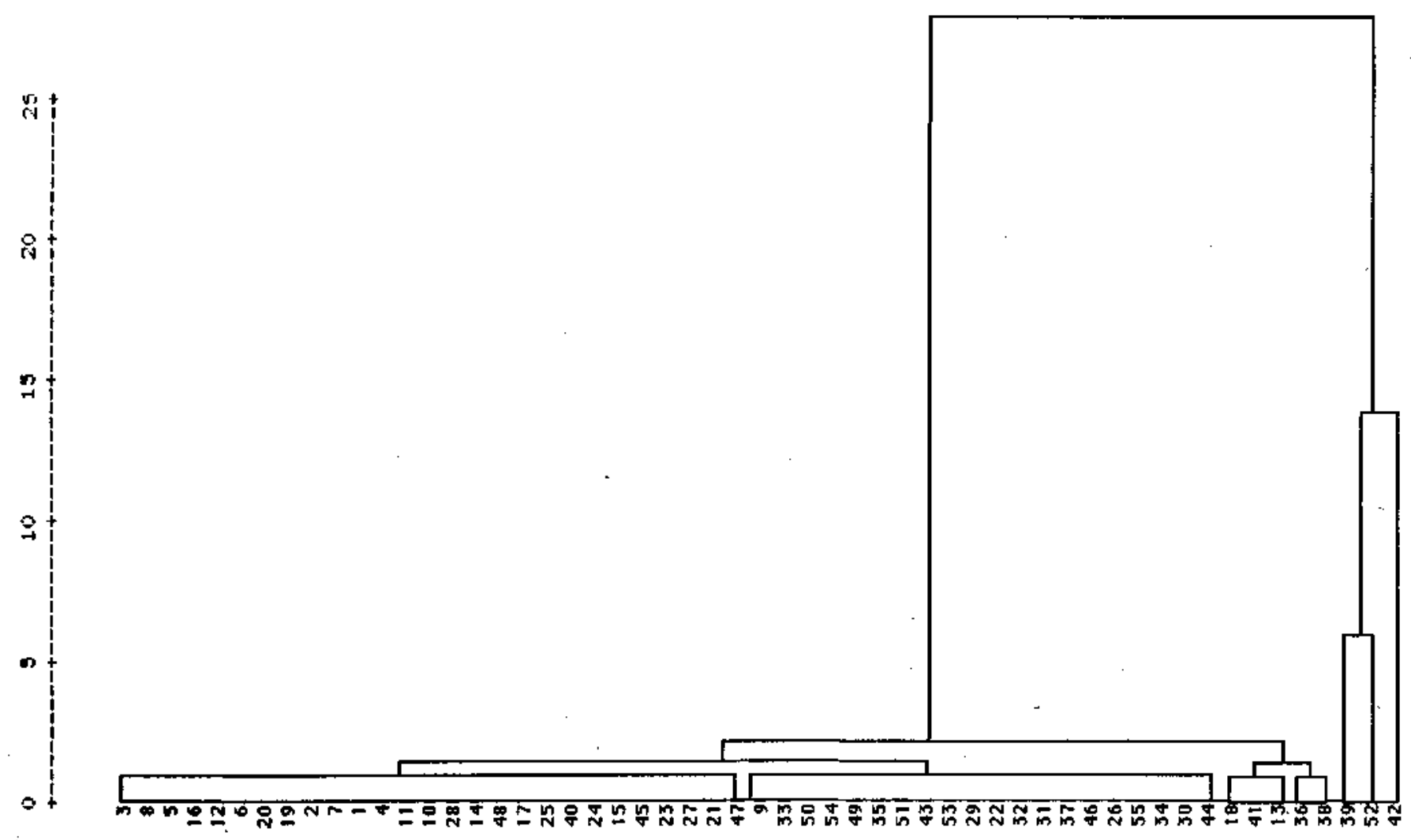

Figura 4 - Amostragem total. Dissemelhança avaliada para $\mathrm{MgO}$, Ni e $\mathrm{Cr}$

Figure 4 - Total sumpling, Diesimilarities evaluated for MgO, Ni and $\mathrm{Cr}$

grama para 52 amostras desenhado para dissemelhanças avaliadas com as habituais nove variáveis. Analisando a distância entre os dois mais dissemelhantes pontos nos agrupamentos que se formam a cada passo, verifica-se agora um intervalo muito menor de variação do que no caso da amostragem completa.

A figura 6 mostra os três dendrogramas que correspondem, respectivamente, a medir as distâncias com base nas variáveis dos grupos de fatores $(\mathrm{Ni}, \mathrm{MgO}, \mathrm{Cr}),\left(\mathrm{Ba}, \mathrm{K}_{2} \mathrm{O}, \mathrm{CaO}\right)$ e $\left(\mathrm{P}_{2} \mathrm{O}_{5}, \mathrm{TiO}_{2}, \mathrm{Y}\right)$. As escalas de dissemelhança são diferentes para cada diagrama, com a dissemelhança máxima das variáveis $\mathrm{F}$ ! (1/5) da correspondente a $\left(\mathrm{P}_{2} \mathrm{O}_{5}, \mathrm{TiO}_{2}, \mathrm{Y}\right)$ e a desta $(1 / 4)$ da correspondente ao $\left(\mathrm{CaO}, \mathrm{Ba}, \mathrm{K}_{2} \mathrm{O}\right)$. A figura 6 mostra como se aglomeram as 52 amostras quando são sucessivamente usadas as variáveis $(\mathrm{MgO}, \mathrm{Ni}, \mathrm{Cr}),\left(\mathrm{Ba}, \mathrm{K}_{2} \mathrm{O}, \mathrm{CaO}\right)$ e $\left(\mathrm{P}_{2} \mathrm{O}_{5}, \mathrm{TiO}_{2}, \mathrm{Y}\right)$ para avaliar as distâncias entre amostras. Extraídas as amostras mais ponderadoras do primeiro fator, como o eram as 39,42 e 52, aparece um diagrama mais dividido no caso da opção $(\mathrm{MgO}, \mathrm{Ni}, \mathrm{Cr})$. Mais importante talvez, é o destaque para a amostra 13 no grupo $\left(\mathrm{Ba}, \mathrm{K}_{2} \mathrm{O}, \mathrm{CaO}\right)$ e das amostras 38 e 49 no fator $\left(\mathrm{P}_{2} \mathrm{O}_{5}, \mathrm{TiO}_{2}, \mathrm{Y}\right)$.

Foi feita, por isso, nova amputação ao grupo de amostras. A figura 7 mostra o agrupamento que se obtém suprimindo a amostra 13.

Os agrupamentos aparecem de novo em número muito maior, já que desapareceram as amostras que fortemente se diferenciavam na coleção global das 55 amostras iniciais.

O comportamento das amostras 38 e 49 , na amostragem total, revela-se peculiar em relação ao grupo $\left(\mathrm{P}_{2} \mathrm{O}_{5}, \mathrm{TiO}_{2}, \mathrm{Y}\right)$. Por isso, e como última redução analítica do número de amostras neste esforço de interpretação das causas de dissemelhança, foi feita uma análise do grupo de 49 amostras (inicial menos as $13,38,39,42,49$ e 52), mostrando-se o dendrograma respectivo na figura 8 .
Interpretação de Agrupamentos As características especiais do conteúdo em ( $\mathrm{Ni}, \mathrm{MgO}, \mathrm{Cr})$, particularmente em Ni e $\mathrm{Cr}$, das amostras 39, 42 e 52, fazem com que estas amostras constituam agrupamento.

A amostragem reduzida permite análise de amostras mais homogêneas. Usando as já referidas nove variáveis, uma análise global expedita de agrupamentos revelou outra amostra singular, a amostra 13 , por ser muito rica em bário, aliás evidenciada, por exemplo, na figura 6 e já observada na matriz de correlação.

Os dendrogramas para 52 amostras evidenciam um clustering muito mais disperso do que os anteriores. Esta realidade é devida ao desaparecimento de amostras que, ao introduzirem distâncias muito grandes na medida das semelhanças achatam a escala das dissemelhanças, isto é, tornam "invisíveis" outras distinções menores.

Os dendrogramas para nove e para todas as variáveis não mostram diferenças essenciais, o que reforça a convicção de que as nove variáveis definidoras dos fatores $F_{1}, \mathrm{~F}_{2}, \mathrm{~F}_{3}$ - que se utilizam na figura 5 - são representativas do comportamento global.

Dedicando atenção separada às amostras $39,42,52$ e 13 considere-se a análise dos agrupamentos referentes às restantes amostras utilizando as nove variáveis básicas do modo que conduziu à figura 7. Considerem-se, sucessivamente, para este efeito, os casos de haver apenas ou dois ou três agrupamentos.

Considerando-se ainda as amostras $13,39,42$ e 52 , o número de agrupamentos assim examinado parece ajustado a posterior correlação geológica, como é mostrado na tabela 9.

Preferindo-se a distribuição das amostras em dois grupos A e B, obtém-se $\mathrm{A}=$ Agrupamento 1 e $\mathrm{B}=$ Agrupamento 2 + Agrupamento 3.

Ao estudar as 55 amostras, pelo mesmo critério e para as 
Figura 5 - Amostragem sem 39, 42 e 52. Dissemelhança avaliada para $(\mathrm{MgO}, \mathrm{Ni}, \mathrm{Cr})+\left(\mathrm{Ba}, \mathrm{K}_{2} \mathrm{O}, \mathrm{CaO}\right)+\left(\mathrm{P}_{2} \mathrm{O}_{5}, \mathrm{TiO}_{2}, \mathrm{Y}\right)$ Figure 5 - Sampling exeluding 39, 42 and 52. Dissimilaritien evaluated for $(\mathrm{MgO}, \mathrm{Ni}, \mathrm{CI})+\left(\mathrm{Ba}, \mathrm{K}_{2} \mathrm{O}, \mathrm{CaO}\right)+\left(\mathrm{P}_{2} \mathrm{O}_{5}, \mathrm{TiO}_{2}, \mathrm{Y}\right)$

mesmas 9 variáveis, chega-se aos agrupamentos que se identificam na tabela 10

A tabela 10 evidencia numericamente o sentido correto de procurar agrupar as amostras sem levar em conta as amostras $13,(39,52)$ e 42 , e serve de verificador das escolhas efetuadas.

Por outro lado se, apesar disso, forem usadas as nove variáveis habituais para fazer o novo clustering, chega-se ao resultado mostrado na figura 8 . Dessa figura e da saída numérica do computador poderiam agrupar-se as amostras do modo que a seguir se resume (tabela 11) para níveis de dissemelhança próximos dos usados anteriormente.

Há apenas ligeiras alterações que podem ser reduzidas à saída das amostras 31 e 37 do agrupamento 3, o que - dentro das aproximações feitas - pode ser considerado como resultado consistente com os anteriores.

\section{CORRELAÇÃO DOS ELEMENTOS ESTATÍSTICOS} COM A GEOLOGIA DO COMPLEXO E CONCLUSÕES A análise de fatores elaborada põe em evidência associações entre variáveis (elementos químicos) que aparecem fundamentalmente agrupadas por $(\mathrm{MgO}, \mathrm{Ni}, \mathrm{Cr}),(\mathrm{Ba}$, $\left.\mathrm{K}_{2} \mathrm{O}\right)$ e $\left(\mathrm{TiO}_{2}, \mathrm{P}_{2} \mathrm{O}_{5}, \mathrm{Y}\right)$. A análise de agrupamentos, por sua vez, ao fazer a associação de amostras de rochas semelhantes, relacionadas no espaço, conduz a uma interpretação geológica por permitir a identificação dos agrupamentos com a posição da rocha no complexo.

As rochas analisadas (55), que representam os tipos litológicos encontrados na porção exposta do Complexo, constituem um associação gabro-anortosítica que corresponde, no estado atual de conhecimentos, à porção média da intrusão. Estas rochas têm textura cumulada típica, sendo os anortosi- tos, seguidos dos troctolitos, as rochas dominantes que têm como minerais cumulus mais abundantes, plagioclásio e olivina.

É de notar que, apesar de ser o plagioclásio o mineral mais abundante nas rochas analisadas, não são os seus elementos essenciais, traduzidos pelas variáveis $\mathrm{SiO}_{2}, \mathrm{Al}_{2} \mathrm{O}_{3}, \mathrm{CaO}$ e $\mathrm{Na}_{2} \mathrm{O}$, que se afiguram como os melhores caracterizadores da amostragem estudada. De fato,eomo pode ser observado nas tabelas das composições desta rochas, os valores de $\mathrm{SiO}_{2}$,como os das demais variáveis em causa $\left(\mathrm{A}_{2} \mathrm{O}_{3}, \mathrm{CaO}\right.$ e $\left.\mathrm{Na}_{2} \mathrm{O}\right)$ não diferem substancialmente do respectivo valor médio no conjunto de 55 amostras, tal como é evidenciado pela tabela 2 , havendo, no entanto, em cada grupo litológico uma variação crescente ou decrescente daquelas variáveis no sentido base-topo da intrusão. $\mathrm{Al}_{2} \mathrm{O}_{3}$ e $\mathrm{CaO}$ exibem correlação negativa com $(\mathrm{MgO}, \mathrm{Ni}$, $\mathrm{Cr})$ e $\left(\mathrm{Ba}, \mathrm{K}_{2} \mathrm{O}\right)$, respectivamente, traduzindo quantidades relativas de olivina e plagioclásio cumulus nas rochas.

$\mathrm{O}$ aparecimento das variáveis $\mathrm{Ba}$ e $\mathrm{K}_{2} \mathrm{O}$, fortemente associadas e em correlação negativa com $\mathrm{CaO}$, no mesmo fator, corresponde à participação do plagioclásio neste fator. Quando se acrescem a este dado os elementos obtidos por análise de agrupamentos, verifica-se que há uma correspondência entre eles, que é identificada como resultante da posição estratigráfica de cada amostra no Complexo. Isto porque é nas rochas da base (parte oeste do Complexo) que o plagioclásio é mais cálcico, com baixos teores em $\mathrm{K}_{2} \mathrm{O}$ e $\mathrm{Ba}$ nas rochas provenientes do topo da parte exposta (leste do Complexo).

A associação $(\mathrm{MgO}, \mathrm{Ni}, \mathrm{Cr})$ reflete o conteúdo de olivina nas rochas em que $\mathrm{MgO}$ é componente essencial e Ni o elemento menor compatível (por excelência). E também nas rochas ricas em. olivina que ocorre magnetita cromífera e 
$n+$

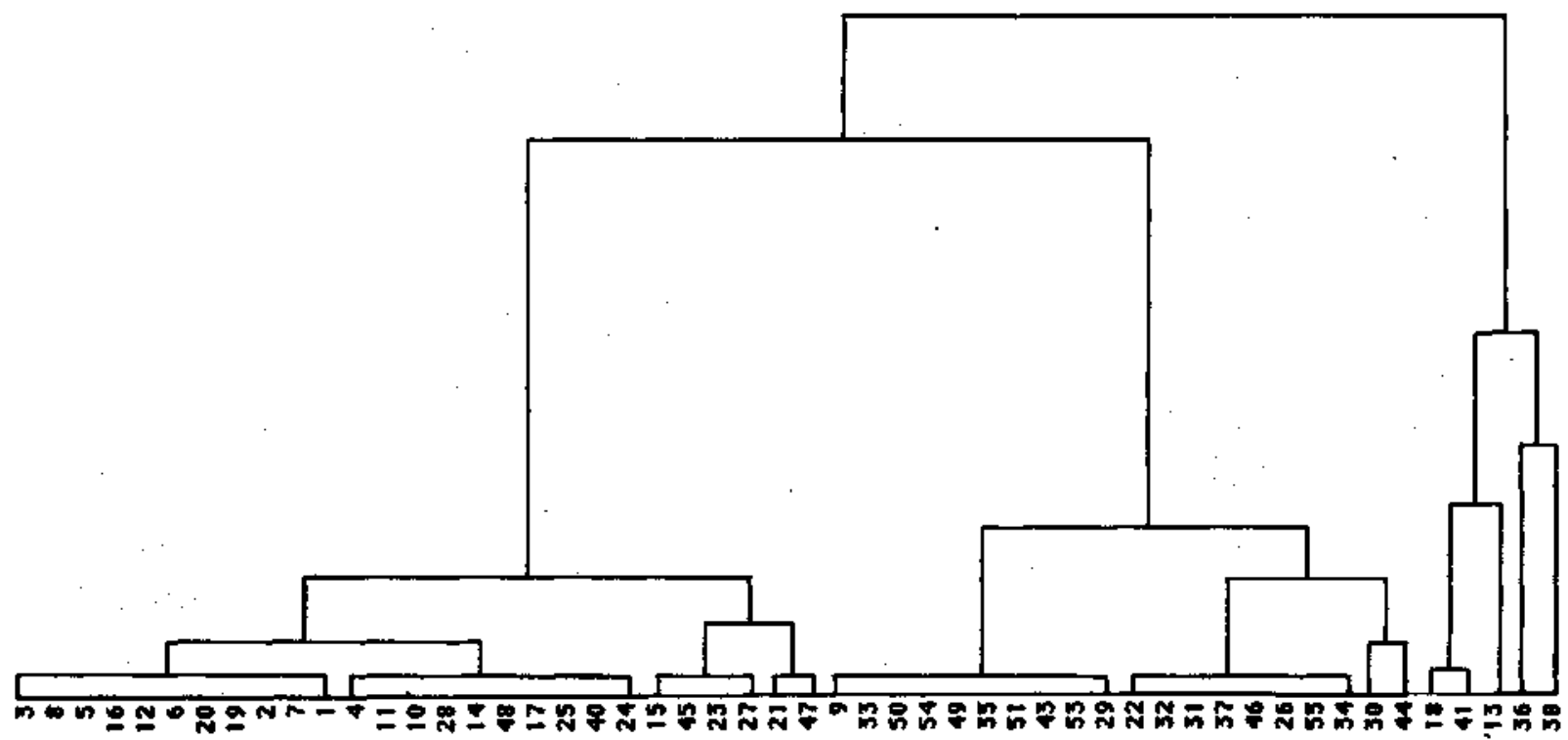

4
0

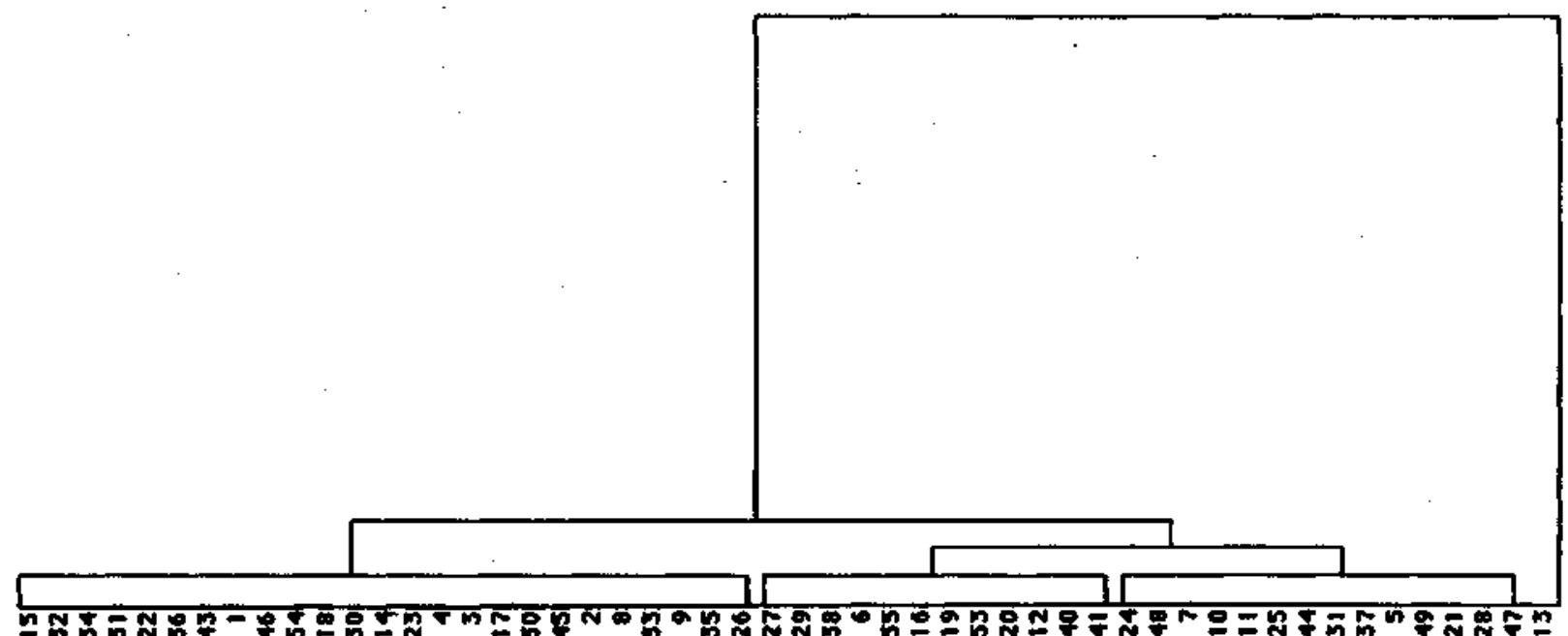

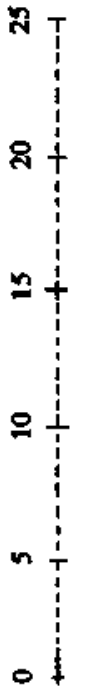

Figura 6 - Amostragem sem 39,42 e 52. Comparação por meio dos fatores: a. $\mathrm{MgO}, \mathrm{Ni}, \mathrm{Cr}$; b. $\mathrm{Ba}, \mathrm{K}_{2} \mathrm{O}, \mathrm{CaO}$; c. $\mathrm{P}_{2} \mathrm{O}_{5}, \mathrm{TiO}_{2}, \mathrm{Y}$ Figure 6 - Sampling excluding 39,42 and 52. Comparison using factors: a. $\mathrm{MgO}, \mathrm{Ni}, \mathrm{Cr}$, b. $\mathrm{Ba}, \mathrm{K}_{2} \mathrm{O}, \mathrm{CaO} ; \mathrm{c} \mathrm{P}_{2} \mathrm{O}_{5}, \mathrm{TiO}_{2}, \mathrm{Y}$ 

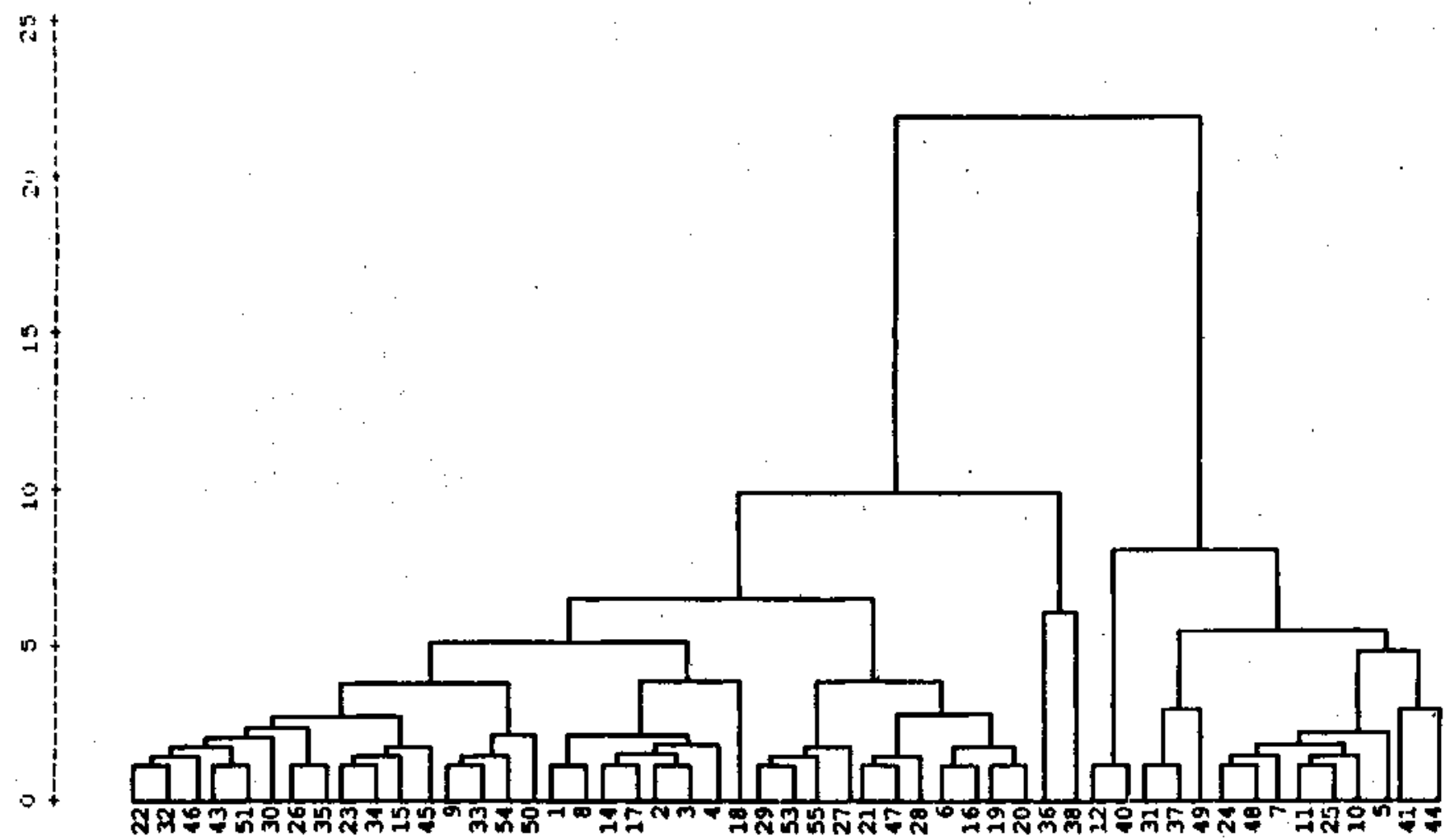

Figura 7 - Amostragem sem 13, 39, 42 e 52. Dissemelhança avaliada para as 9 variáveis (Escala vertical distorcida) Figure 7 - Sampling excluding 13,39,42 and 52. Dissimilarities evaluated for the 9 variables (Distorted vertical scale)
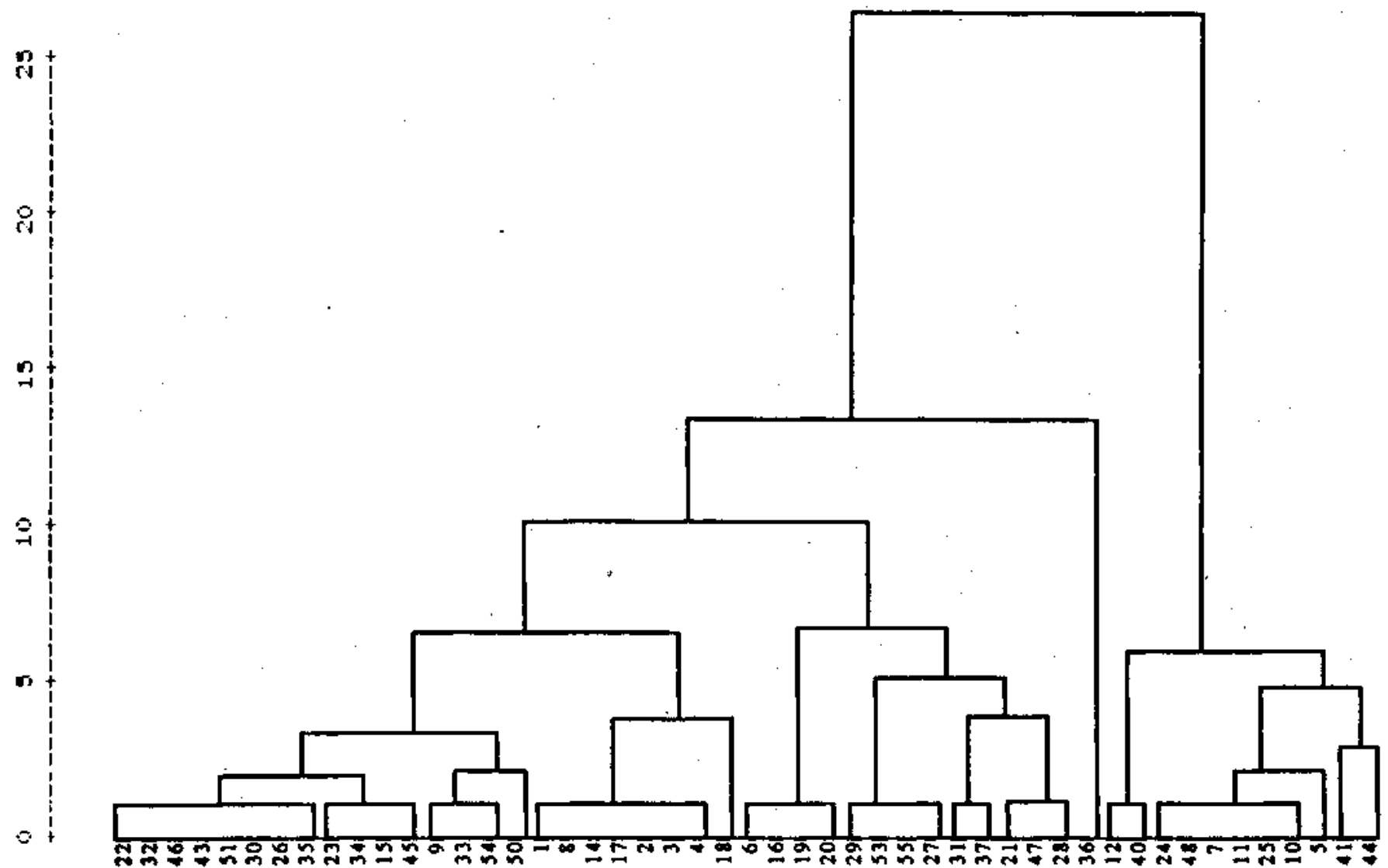

Figura 8 - Amostragem sem 13, 38, 39, 42, 49 e 52. Dissemelhança avaliada para as 9 variáveis

Figure 8 - Sampling excluding 13,38,39,42,49 and 52. Dissimilarities evaluated for 9 variables 
Tabela 9-Três agrupamentos - 51 amastras Table 9 - Throe cluntern - 51 smples

\begin{tabular}{|c|l|}
\hline Agnupamentos & \multicolumn{1}{|c|}{ Amostuas } \\
\hline 1 & $22,32,46,43,51,39,26,35,23,34,15,45,9,33,54,50,1{ }^{*}$ \\
& $8,14,17,2,3,4,18,29,53,55,27,21,47,28,6,16,19,20$ \\
\hline 2 & 36,38 \\
\hline 3 & $31,37,49,24,48,7,11,25,10,5,41,44,12,40$ \\
\hline
\end{tabular}

Tabela 10-Agrupamentos - 55 amostras Table 10-Clusters - 55 samples

\begin{tabular}{|c|l|}
\hline Agrupamentos & \multicolumn{1}{|c|}{ Amostras } \\
\hline 1 & $22,32,43,46,51,30,26,35,23,34,15,45,9,33,54,50,1$, \\
& $8,14,17,2,3,4,18,29,53,55,27,21,47,28,6,36,19,20$ \\
\hline 2 & 36,38 \\
\hline 3 & $12,40,31,37,49,24,48,7,11,25,10,5,41,44$ \\
\hline 4 & 39,52 \\
\hline 5 & 13 \\
\hline 6 & 42 \\
\hline
\end{tabular}

Tabela II - Agripanentos - 49 amostras

Table 11 - Clutters = 49 amples

\begin{tabular}{|c|l|}
\hline Agnupamentos & \multicolumn{1}{|c|}{ Amostras } \\
\hline 1 & $22,32,46,43,51,30,26,35,23,34,15,45$ \\
& $9,33,54,50,1,8,14,17,2,3,4,18$ \\
\hline 2 & $6,16,19,20,29,53,55,27,31,37,21,47,28$ \\
\hline 3 & 36 \\
\hline 4 & $12,40,24,49,7,11,25,10,5,41,44$ \\
\hline
\end{tabular}

cromita, daí a afinidade salientada naquela associação.

$\mathrm{O}$ significado geológico da associação $\left(\mathrm{TiO}_{2}, \mathrm{P}_{2} \mathrm{O}_{5}, \mathrm{Y}\right)$, ao contrário das anteriores, é menos evidente, uma vez que a presença destes elementos está relacionada com minerais menos abundantes em alguns tipos litológicos ou praticamente ausentes em outros.

Em resumo, no essencial, a análise de fatores das rochas do Complexo Gabro-Anortosítico de Angola foi feita em amostragem constituída por 55 rochas representativas dos tipos litológicos que ocorrem naquela intrusão, provenientes de toda a área de exposição, utilizando-se 23 variáveis. Constatou-se que apenas nove dessas variáveis são suficientes para definir o comportamento geoquímico do Complexo, desde que adequadamente combinadas e condensadas em três fatores.

Esta constatação compreende-se pela natureza estratiforme do Complexo e o caráter cumulado das rochas que o constituem. Em decorrência destes dois fatores, resulta que a fase olivina cumulus controla a química das rochas em que ela está presente enquanto que nas rochas mais ricas em plagioclásio, especialmente nos anortositos, é a fase plagioclásio cumulus que exerce aquele controle. Este comportamento está patente no modo como $\mathrm{MgO}, \mathrm{Ni}, \mathrm{Cr}$ se apresentam fortemente associados e, analogamente, $\mathrm{K}_{2} \mathrm{O}$, $\mathrm{Ba}$ e $(\mathrm{CaO})$. São associações que refletem efeitos opostos dos minerais olivina e plagioclásio na química do conjunto das rochas do Complexo. A associação $\mathrm{TiO}_{2}, \mathrm{P}_{2} \mathrm{O}_{5}$, Y reflete a contribuição destes elementos nas fases intercumulus, geralmente representada por piroxênio e que, nas rochas do Complexo, têm pequena representatividade.

$\mathrm{Na}$ análise de agrupamentos, também resumidamente, é possível concluir que a associação de amostras com afinidades geoquímicas é feita de tal modo que agrega, de maneira muito clara e com apenas exceções pontuais, amostras de rochas que provêm da base (oeste) ou do topo Oeste) da porção exposta do Complexo.

Esta é uma conclusão importante na seqüência de estudos futuros deste corpo intrusive e que serve de orientação para a investigação de possíveis ocorrências minerais de significado econômico.

\section{REFERÊNCIAS BIBLIOGRÁFICAS}

BATHE, K. J. \& WILSON, E.L. 1976. Numerical Methods in Finite Element Analysis. Prentice Hall. $528 \mathrm{p}$.

DAVIS, J. C. 1986. Statistics and Data Analysis in Geology. New York, Wiley \& Sons. $646 \mathrm{p}$.

NORUSIS, M. J. 1986. Advanced Statistics. SPSS Inc.

SILVA, Z. C. G. 1987. Plagioclases of the anorthosites from Southwest Angola. In: MATHEIS, J. \& SCHANDELMEIR, H. ed. Current Research in African Earth Sciences. 486 p.

SILVA, Z. C. G. 1988. Evolution of the gabbro - anorthosite Complex of SW Angola based on petrochemical data. In: SIMPOSIUM ON GONDWANA, 7, São Paulo, (no prelo).

SILVA, Z. C, G. 1980. Geochemistry of the gabbro - anorthosite Complex of Angola. Journal African Earth Sciences, 10(4):683-692.
SIMPSON, E. S. W. 1970. The anorthosite of Southern Angola: A review of present data. In: CLIFFORD, T. N. \& GASS I. G. ed. African Magmatism and Tetocnics. $461 \mathrm{p}$.

SNEATH, P. H. A. \& SOKAL, R. R. 1973. Numerical Taxonomy. Freeman \& Company. 573p.

MANUSCRITO A609 Recebido em 06 de julho de 1989 Revisão do autor em 05 de fevereiro de 1990 Revisão aceita em 13 de fevereiro de 1990 